\title{
Original
}

\section{Influence of Hepatectomy on Body Temperature Change in Rats}

\author{
Amane OtAкI ${ }^{* 1)}$, Satoko AвE ${ }^{1)}$, Kenji Mishima ${ }^{2)}$, \\ Kazuhiko SoEJIMA $^{1)}$ and Kazuhito AsAnO ${ }^{1)}$
}

\begin{abstract}
Abdominal surgery, especially liver resection and transplantation, increases body temperature during and after surgery, but the precise mechanism (s) underlying this effect are not well understood. The present study thus sought to investigate this phenomenon using an experimental rat model. Specific pathogenfree male Sprague-Dawley rats, 5 weeks of age, underwent a two-thirds partial hepatectomy $(\mathrm{PH})$, one-third splenectomy, or left kidney resection, and then rectal temperature was measured for 5 consecutive days after surgery. Rectal temperature increased in $\mathrm{PH}$ rats to a peak on day 4, but no change in temperature was detected after splenectomy and kidney resection. In the second part of the study, we examined the influence of gadolinium chloride and interleukin- $1 \beta$ monoclonal antibody (IL-1 $\beta \mathrm{mAb}$ ) on the increase in rectal temperature following PH. Treatment of rats with $20 \mathrm{mg} / \mathrm{kg}$ gadolinium chrolide or $200 \mu \mathrm{g}$ IL- $1 \beta \mathrm{mAb}$ inhibited the $\mathrm{PH}$-induced increase in rectal temperature and decrease in IL- $1 \beta$ and prostaglandin E2, which act as pyrogens to change the thermoregulatory set point in the hypothalamus. These results suggest that abdominal surgery, especially liver resection, caused an increase in endogenous pyrogen production that results in increased body temperature.
\end{abstract}

Key words : body temperature, hepatectomy, IL-1 $\beta$, prostaglandin E2, Kupffer cell

\section{Introduction}

As warm-blooded animals, human organs are designed to operate efficiently at a body temperature around $37^{\circ} \mathrm{C}^{1)}$, with natural variations throughout the day remaining within $1^{\circ} \mathrm{C}$. The body uses a complex mechanism for thermoregulation and generates heat through the process of metabolism, which generates the energy essential to maintain biological activities. Decreased body temperature after surgery is a well-known outcome in many patients ${ }^{2,3)}$, because surgery is an invasive process that can induce a shock effect to the body ${ }^{4,5}$. In addition, the temperature of the body at rest is slightly lower than while active and most surgical suites are air-conditioned and tend to be very cold ${ }^{3)}$. Surgery also causes blood loss, which will further decrease body temperature. In some cases, surgery may be performed to remove an organ or organ system from the body. Therefore, a decrease in postoperative body temperature is caused

\footnotetext{
1) Showa University Graduate School of Nursing and Rehabiritation Sciences, 1865 Touka-Ichiba, Midori-Ku, Yokohama 226-8555, Japan.

2) Department of Oral Pathology, Showa University School of Dentistry.

* To whom corresponding should be addressed.
} 
by a combination of these factors as the body struggles to maintain temperature, while healing surgical wounds. Furthermore, body temperature after surgery may decrease in response to medication administered both before and during procedures ${ }^{3,6}$, while the lack of activity when the patient is on the operating table will slow metabolism and lower heat generation within the body ${ }^{5)}$. After surgery, a patient's body temperature is maintained with heated blankets because low postoperative body temperature can cause complications if not corrected promptly. Within a few hours, the individual usually regains the ability to self-regulate body temperature as the effects of anesthesia wear off. Abdominal surgeries, especially liver resection and transplantation, can increase body temperature during surgery. It is reported that liver resection causes the activation of Kupffer cells to produce $\mathrm{IL}_{-1}{ }^{7)}$, which can affect changes in body temperature ${ }^{8)}$, suggesting that IL-1 from Kupffer cells increases the body temperature of patients. However, there is no direct evidence that IL-1 from Kupffer cells causes the increase in body temperature. Therefore, the aim of the present study was to examine the possible mechanisms by which abdominal surgery increases body temperature using an experimental rat model.

\section{Materials and methods}

\section{Animals}

Specific pathogen-free male Sprague-Dawley rats, 5 weeks of age, were purchased from Charles River Laboratories Japan, Inc. (Atsugi, Kanagawa, Japan) and maintained in our animal facility under a controlled environment $\left(25 \pm 2^{\circ} \mathrm{C}, 55 \pm 5 \%\right.$ humidity, and 12-h dark/light cycle $)$. All experimental procedures were approved by the Animal Care and Use Committee of Showa University (approval no. : 54001).

\section{Surgical Operation}

Two-thirds partial hepatectomy $(\mathrm{PH})$ was performed according to the methods described by Higgins and Anderson ${ }^{9)}$. Briefly, rats were anesthetized by intraperitoneal injection of pentobarbital (30 mg/ kg; Kyoritsu Seiyaku Corp., Tokyo, Japan). After the abdominal hair was shaved and the abdominal skin was sterilized with $70 \%$ ethanol and povidone iodine (Meiji Seika Co., Ltd., Tokyo, Japan), an incision of approximately $3 \mathrm{~cm}$ was made into the abdominal wall and two-thirds of the liver was removed. Afterward, each $\mathrm{PH}$ rat received three daily intraperitoneal injections of cefazolin sodium hydrate $(40 \mathrm{mg} / \mathrm{kg}$; Fujisawa Pharmaceutical Co., Ltd., Tokyo, Japan) to prevent postoperative bacterial infection. To prepare the partial splenectomy and kidney resection rat models, rats were pre-treated in a similar manner and then either approximately one-third of the spleen or the left kidney was resected. Rats subjected to abdominal wall treatment only (hair removal and incision) were used as sham-operated controls. Postoperatively, these rats also received three daily intraperitoneal injections of cefazolin sodium hydrate (40 mg/kg; Fujisawa Pharmaceutical Co., Ltd.) to prevent bacterial infection.

Treatment of rats with agents

$\mathrm{PH}$ rats received either $200 \mu \mathrm{g}$ of interleukin- $1 \beta$ monoclonal antibody (IL-1 $\beta \mathrm{mAb}$ ) or 
$20 \mathrm{mg} / \mathrm{kg}$ gadolinium chloride intravenously 4 days after surgery. The dose of gadolinium chloride used in this study showed no toxicological effects when injected intravenously into rats $^{10,11)}$. Both agents were purchased from R \& D Systems, Inc. (Minneapolis, MN, USA) as preservative-free reagents.

\section{Measurement of rectal temperature}

Rectal temperature was measured using a thermal probe connected to a digital thermometer (Tateyama Kagaku Industry Co., Ltd., Toyama, Japan). Rats were anesthetized with an intraperitoneal injection of pentobarbital $(30 \mathrm{mg} / \mathrm{kg}$; Kyoritsu Seiyaku Corp.). A thermistor probe (Tateyama Kagaku Industry Co., Ltd.) was then inserted about $2 \mathrm{~cm}$ into the rectal and left in place for $1 \mathrm{~min}$ to record the temperature.

\section{Assay for interleukin (IL) $-1 \beta$ and prostaglandin $(P G)$ E2}

Serum IL-1 $\beta$ and PGE2 levels were measured using commercially available enzyme-linked immunosorbent assay (ELISA) kits according to the manufacturer's recommendations. The ELISA test kits for IL- $1 \beta$ were purchased from R \& D Systems and those for PGE2 from Cayman Chemical Company (Ann Arbor, MI, USA). The minimum detectable levels of these ELISA kits were $5.0 \mathrm{pg} / \mathrm{ml}$ for IL- $1 \beta$ and $7.8 \mathrm{pg} / \mathrm{ml}$ for PGE2.

\section{Statistical analysis}

All data are expressed as the mean \pm SE of five rats. Significant differences between control and experimental groups were identified by analysis of variance followed by the Bonferroni test. A probability $(P)$ value $<0.05$ was considered statistically significant.

\section{Results}

Influence of abdominal surgery on core body temperature

Rats that underwent $\mathrm{PH}$ underwent a rectal temperature measurement once a day (from 11:00 to 12:00) for 5 consecutive days. As shown in Fig. 1, the rectal temperature of $\mathrm{PH}$ rats was significantly increased on day 1 , plateaued by day 4 , and declined thereafter. To then examine whether splenectomy and kidney resection also caused an increase in body temperature, the rectal temperature of rats in the splenectomy and kidney resection groups was measured 4 days after surgery. As shown in Fig. 2, there were no significant differences in rectal temperature between rats in the splenectomy $\left(36.4 \pm 0.10^{\circ} \mathrm{C}\right)$ and kidney resection $\left(36.4 \pm 0.08^{\circ} \mathrm{C}\right)$ groups and controls $\left(36.0 \pm 0.31^{\circ} \mathrm{C}\right)$.

\section{Influence of gadolinium chloride and IL-1 $\beta$ mAb treatment on rectal temperature of $P H$ rats}

We next examined whether gadolinium chloride or IL-1 $\beta$ mAb treatment suppressed the increase in rectal temperature following $\mathrm{PH}$. Preliminary experiments confirmed that intravenous injection of either gadolinium chloride or IL- $1 \beta \mathrm{mAb}$ into non-treated rats caused no changes in rectal temperature (data not shown). Rats in the $\mathrm{PH}$ group received an intravenous injection 


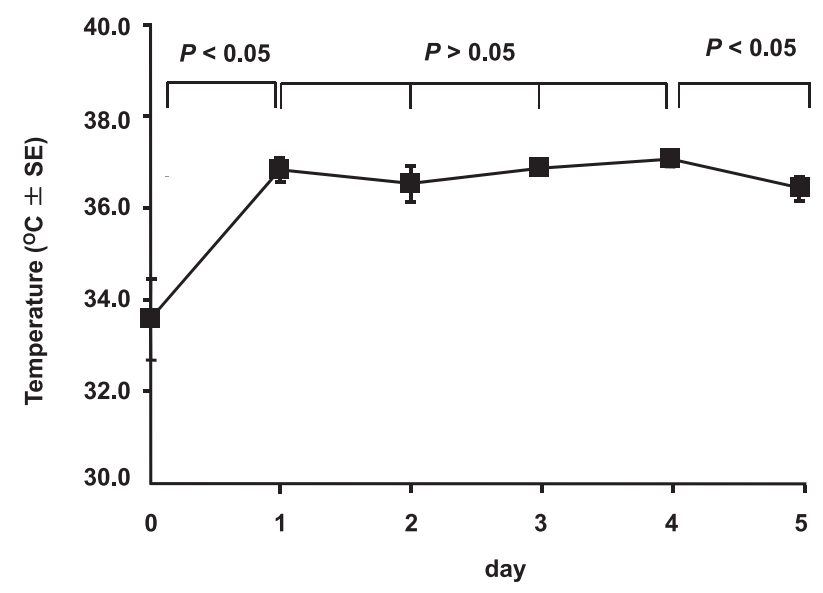

Fig. 1. Influence of partial hepatectomy on body temperature fluctuations in rats. Rats underwent a 2/3 partial hepatectomy on day 0 . Rectal temperature was measured before surgery (day 0 ) and at 1, 2, 3, 4, and 5 days after surgical operation. The data are expressed as the mean $\pm \mathrm{SE}$ of five rats.

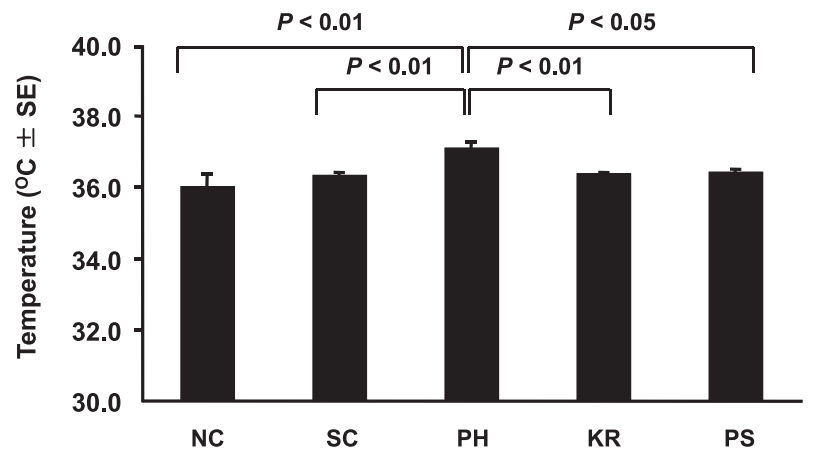

Fig. 2. Influence of partial hepatectomy, partial splenectomy, and kidney resection on body temperature. Groups of rats underwent a 2/3 partial hepatectomy, one-third splenectomy, or left kidney resection on day 0 . The rectal temperature was measured on day 4 . The data are expressed as the mean $\pm \mathrm{SE}$ of five rats.

NC: Normal Control; SC: Sham Control ; $\mathrm{PH}$ : Partial hepatectomy; PS : partial splenectomy; KR : kidney resection.

of gadolinium chloride 4 days after surgery and rectal temperature was measured $2 \mathrm{~h}$ later, and as shown in Fig. 3A, the injected rats showed a significantly suppressed increase in rectal temperature $\left(37.1 \pm 0.11^{\circ} \mathrm{C}\right)$ induced by $\mathrm{PH}$, compared with non-treated controls $\left(36.0 \pm 0.32^{\circ} \mathrm{C}\right)$. Similar experiments to examine the influence of IL- $1 \beta$ mAb injection on $\mathrm{PH}$ rats showed an inhibition of the $\mathrm{PH}$-induced increase in rectal temperature $\left(37.3 \pm 0.06^{\circ} \mathrm{C}\right)$ compared to shamoperated controls $\left(36.0 \pm 0.32^{\circ} \mathrm{C}\right)$ (Fig. 3B).

\section{Influence of gadolinium chloride or IL-1 $\beta$ mAb treatment on PGE2 and IL-1 $\beta$ levels in PH rats}

The third set of experiments was designed to examine the influence of $\mathrm{PH}$ on the production of endogenous pyrogens, which increase the core body temperature of mammals. Furthermore, we also examined the influence of pyrogen suppression on changes to core body temperature. Briefly, serum was obtained from $\mathrm{PH}$ rats before and after treatment with gadolinium chloride or IL- $1 \beta \mathrm{mAb}$, and then assayed for both PGE2 and IL-1 $\beta$ by ELISA. As shown in Fig. 4A $\& \mathrm{~B}$, gadolinium chloride treatment significantly decreased serum levels of both PGE2 (314.10 \pm $22.57 \mathrm{pg} / \mathrm{ml})$ and IL-1 $\beta(13.00 \pm 2.52 \mathrm{pg} / \mathrm{ml})$, which were increased by PH (PGE2: $480.77 \pm$ $25.80 \mathrm{pg} / \mathrm{ml} ; \mathrm{IL}-1 \beta: 40.45 \pm 9.51 \mathrm{pg} / \mathrm{ml}$ ). The data in Fig. 5 (A \& B) also showed that IL- $1 \beta$ $\mathrm{mAb}$ treatment decreased serum PGE2 levels $(351.00 \pm 27.62 \mathrm{pg} / \mathrm{ml})$, which were increased by $\mathrm{PH}(469.20 \pm 30.16 \mathrm{pg} / \mathrm{ml})$. On the other hand, kidney resection did not influence serum pyrogen levels (Fig. 6), with PGE2 and IL-1 $\beta$ levels in serum obtained from rats 4 days after kidney resection (PGE2 : $413.50 \pm 31.89 \mathrm{pg} / \mathrm{ml}$; IL-1 $\beta: 6.93 \pm 3.58 \mathrm{pg} / \mathrm{ml}$ ) nearly identical to those obtained before surgery (PGE2 : $416.70 \pm 12.82 \mathrm{pg} / \mathrm{ml}$; IL-1 $\beta: 6.90 \pm 3.47 \mathrm{pg} / \mathrm{ml}$ ). 

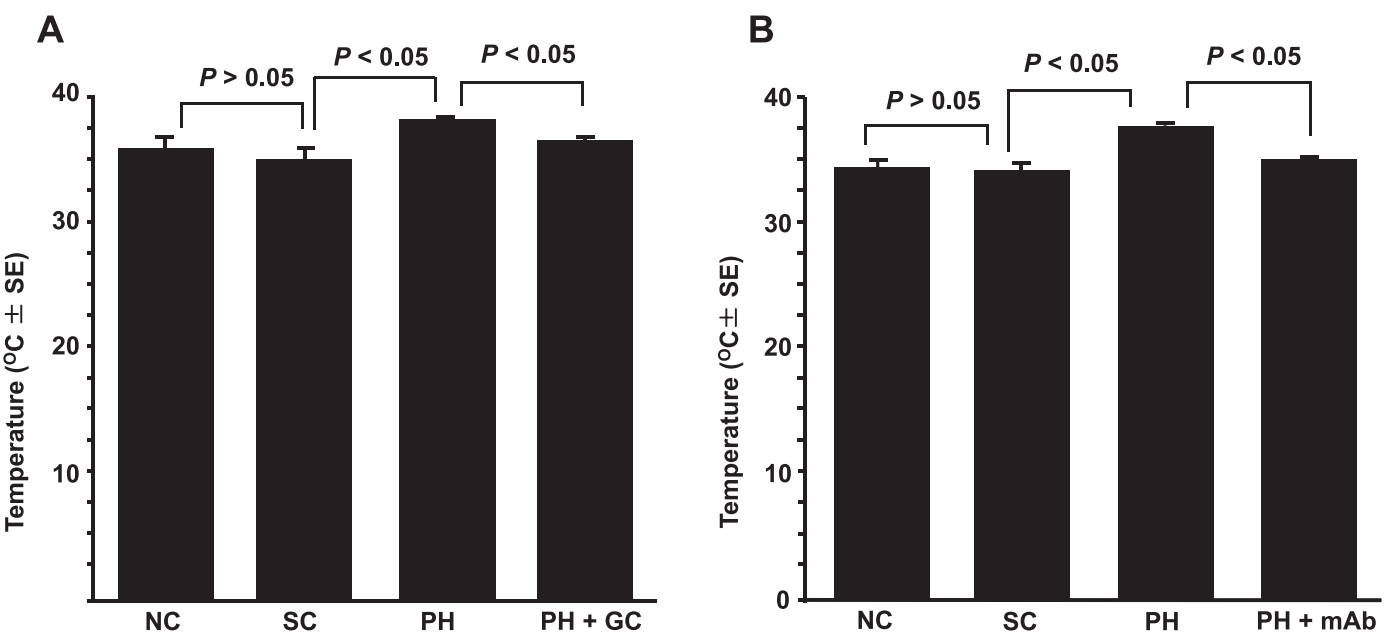

Fig. 3. Influence of treatment with gadolinium chloride $(\mathrm{GC})$ or interleukin- $1 \beta$ monoclonal antibody (IL-1 $\beta \mathrm{mAb}$ ) on body temperature of partial hepatectomized (PH) rats. PH rats were intravenously injected with either $20 \mathrm{mg} / \mathrm{kg}$ GC or $200 \mu \mathrm{g}$ IL- $1 \beta \mathrm{mAb}$ on day 4 and rectal temperature was measured $2 \mathrm{~h}$ later. The data are expressed as the mean \pm SE of five rats. NC: Normal Control ; SC : Sham Control ; PH : Partial hepatectomy.

A

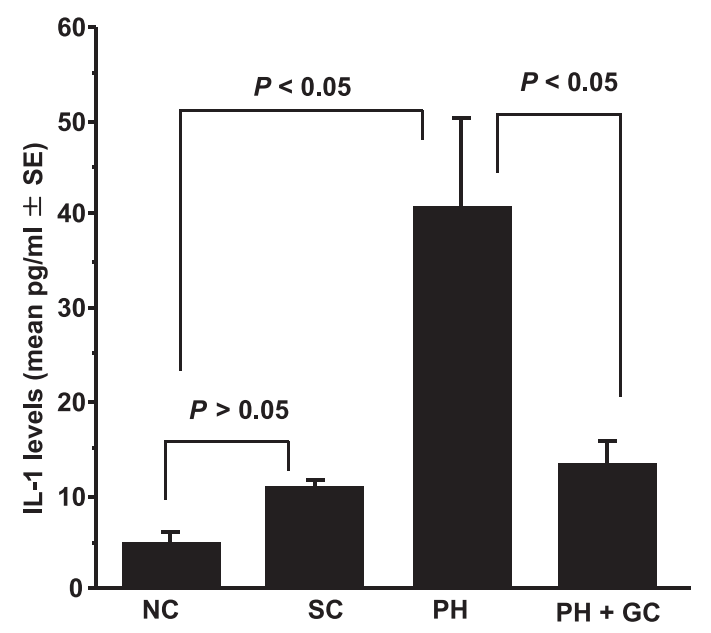

B

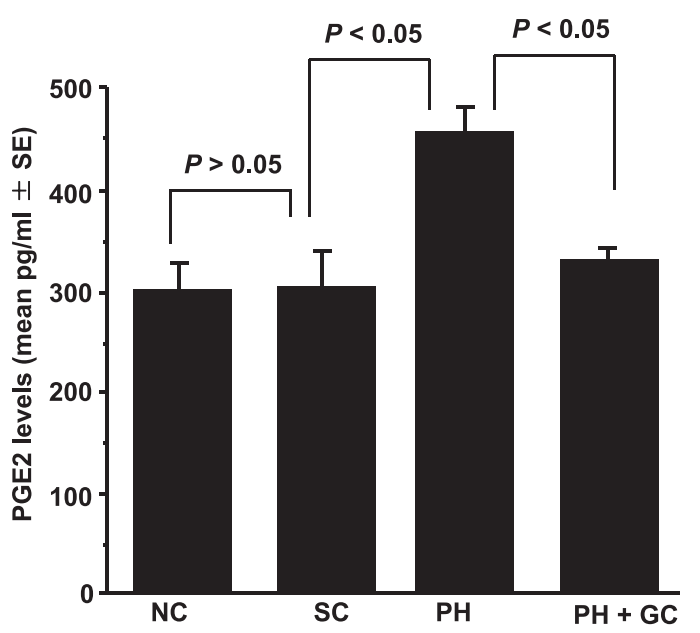

Fig. 4. Influence of treatment with gadolinium chloride (GC) on serum levels of interleukin (IL) $-1 \beta$ (A) and prostaglandin E2 (B) in partial hepatectomized ( $\mathrm{PH}$ ) rats. $\mathrm{PH}$ rats were intravenously injected with $20 \mathrm{mg} / \mathrm{kg}$ GC on day 4. Serum samples were obtained $2 \mathrm{~h}$ later and PGE2 and IL-1 $\beta$ levels were examined by ELISA. The data are expressed as the mean $\pm \mathrm{SE}(\mathrm{pg} / \mathrm{ml})$ of five rats. NC: Normal Control; SC: Sham Control; PH : Partial hepatectomy.

\section{Discussion}

Surgical procedures are well known to lower core body temperature by $0.5-1.5^{\circ} \mathrm{C}$, owing in part to cold operating rooms, decreased muscular activity, and restricted cutaneous vasodilation $^{3,6)}$. Although abdominal surgery is known to cause transient increases in body temperature, the mechanisms that drive these fluctuations in body temperature are not well 
A

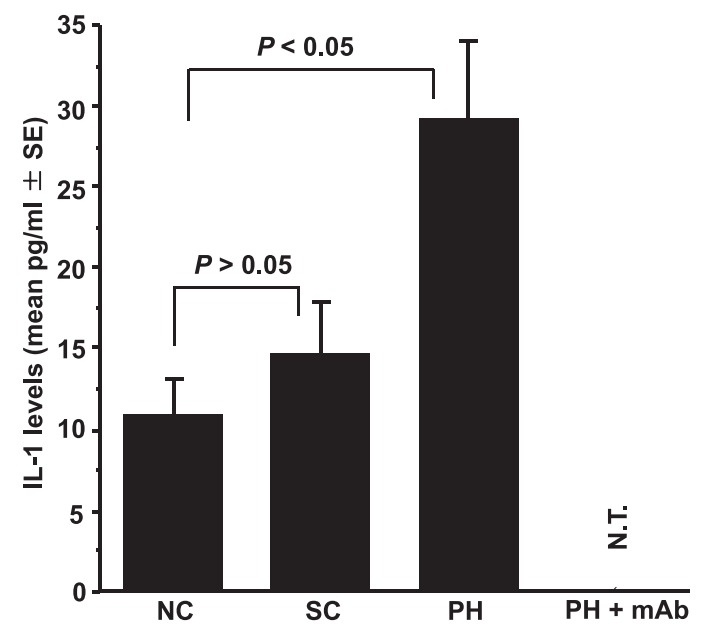

B

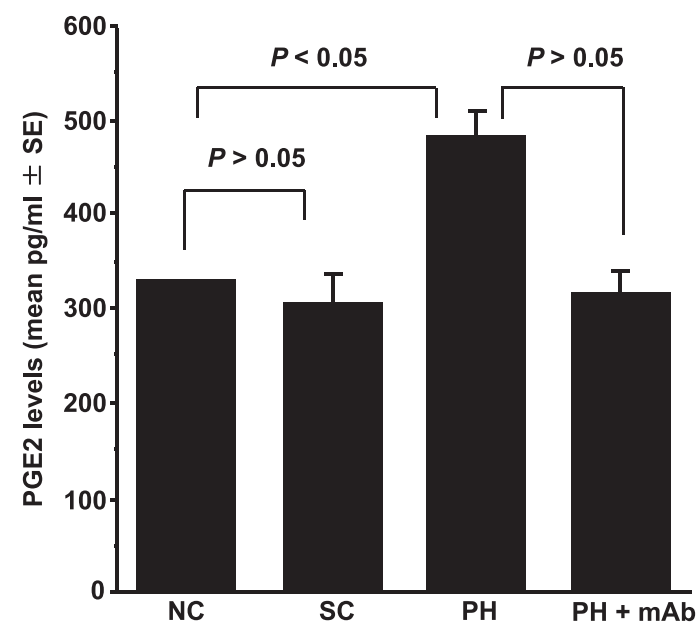

Fig. 5. Influence of treatment with interleukin (IL) $-1 \beta$ monoclonal antibody (IL-1 $\beta \mathrm{mAb}$ ) on serum levels of IL-1 $\beta$ (A) and prostaglandin E2 (B) of partial hepatectomized (PH) rats. $\mathrm{PH}$ rats were intravenously injected with $200 \mu \mathrm{g}$ IL- $1 \beta \mathrm{mAb}$ on day 4 . Serum samples were obtained $2 \mathrm{~h}$ later and the contents of both PGE2 and IL-1 $\beta$ were examined by ELISA. The data are expressed as the mean $\pm \mathrm{SE}(\mathrm{pg} / \mathrm{ml})$ of five rats. NC : Normal Control ; SC : Sham Control ; PH : Partial hepatectomy; N.T. : Not Tested ; $\mathrm{mAb}$ : monoclonal antibody.

A

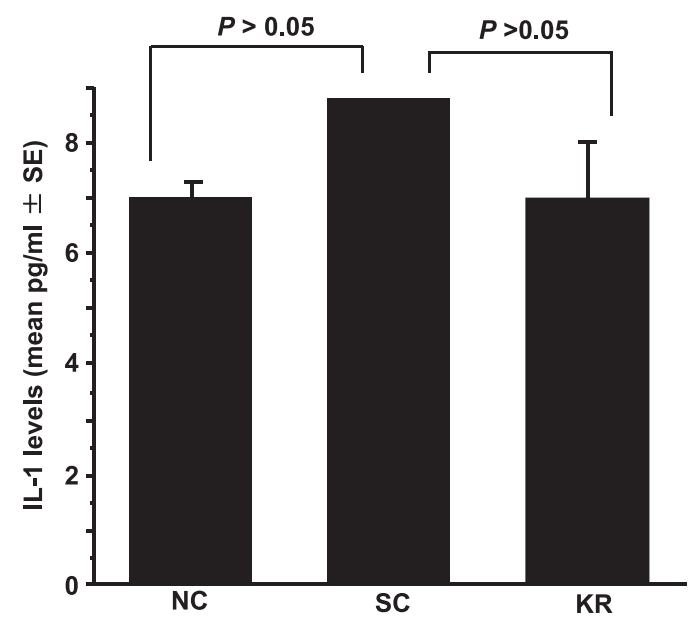

B

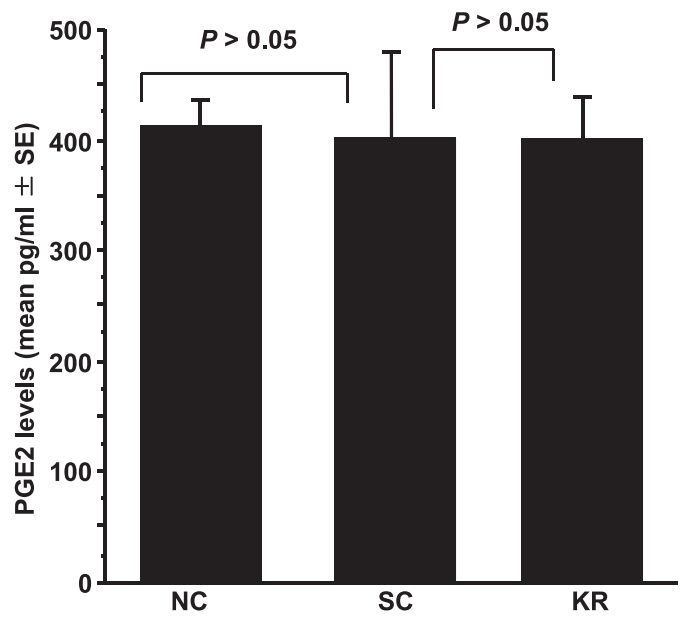

Fig. 6. Influence of kidney resection on serum levels of interleukin (IL) $-1 \beta$ and prostaglandin (PG) E2. The left kidney was removed from each rat and serum samples were obtained 4 days later. IL-1 $\beta$ and PG E2 levels were examined by ELISA. The data are expressed as the mean $\pm \mathrm{SE}(\mathrm{pg} / \mathrm{ml})$ of five rats. NC: Normal Control ; SC: Sham Control; KR : kidney resection.

understood $^{5)}$. The aim of the present study was therefore to identify possible mechanisms through which abdominal surgery increases body temperature using experimental rat models.

The present results clearly showed that $\mathrm{PH}$, but not splenectomy or kidney resection, increased rectal temperature. The mammalian liver reportedly possesses the unique ability to regenerate 
to nearly its original size after $\mathrm{PH}$ or injury ${ }^{12,13)}$. The proliferative signals responsible for liver regeneration are conveyed by a complex network of cytokines and growth factors, which induce hepatocytes to proliferate ${ }^{12)}$. In a study to identify cell types and mediators that stimulate hepatocyte proliferation, Goss et $a l^{13)}$ showed that Kupffer cells, resident macrophages in the liver, obtained from $\mathrm{PH}$ rats were significantly activated relative to macrophages obtained from the spleen, peritoneum, and airways. This group also observed that Kupffer cells from PH rats produced much higher levels of both IL-1 and PGE2 in response to lipopolysaccharide stimulation in vitro ${ }^{13}$.

Increases in body temperature induce changes to the thermoregulatory set point in the hypothalamus, via the direct action of many types of mediators, which include IL- $1 \beta$, tumor necrosis factor, and IL-6 ${ }^{8,14}$. These endogenous pyrogens trigger the synthesis and release of other mediators, most notably PGE2, in the preoptic nuclei of the anterior hypothalamus $\left.{ }^{15}{ }^{16}\right)$ and in vascular endothelial cells, among other regions ${ }^{1)}$. Preoptic neurons bearing E-prostanoid receptors alter their intrinsic firing rate in response to PGE2 stimulation, evoking an elevation in the thermoregulatory set point ${ }^{1)}$. Together with these reports, the present data might indicate that $\mathrm{PH}$ in rats activates Kupffer cells to produce IL- $1 \beta$ and PGE2, which, in turn, raise the thermoregulatory set point in the hypothalamus and subsequently, the body temperature.

We then asked how exactly the $\mathrm{PH}$ procedure, but not splenectomy or kidney resection, could increase body temperature. To do this, we first examined the influence of inhibiting Kupffer cell activation on body temperature fluctuations using gadolinium chloride, which can inhibit calcium ion uptake and calcium-dependent cellular responses such as nuclear factor kappa-B (NF- $\kappa \mathrm{B}$ ) activation responsible for protein production, including IL-1 and PGE2 ${ }^{10,11}{ }^{17}$. The present data clearly showed that gadolinium chloride treatment prevented the PH-induced increases in body temperature in rats and also suppressed the serum levels of both PGE2 and IL- $1 \beta$, which play essential roles in modulating body temperature and which were raised by PH. Furthermore, IL-1 $\beta$ mAb treatment of PH rats inhibited the increase in both body temperature and PGE2 production. These results strongly suggest that $\mathrm{PH}$ activated Kupffer cells, and that these cells, in turn, increased the production of the endogenous pyrogens IL-1 $\beta$ and PGE2 to induce a net increase in body temperature. This speculation is supported by the observation that kidney resection did not cause changes to serum levels of the endogenous pyrogens IL-1 $\beta$ and PGE2.

In conclusion, the increase in body temperature induced by $\mathrm{PH}$, but not by splenectomy and kidney resection, could be attributed, at least in part, to Kupffer cell activation.

\section{Conflict of interest}

The authors declare no conflict of interest regarding this work.

\section{References}

1) Aronoff DM, Neilson EG. Antipyretics: mechanisms of action and clinical use in fever suppression. Am J Med. 2001;111:304-315. 
2) Han SB, Gwak MS, Choi SJ, et al. Effect of active airway warming on body core temperature during adult liver transplantation. Transplant Proc. 2013;45:251-254.

3) Andrzejowski J, Hoyle J, Eapen G, et al. Effect of prewarming on post-induction core temperature and the incidence of inadvertent perioperative hypothermia in patients undergoing general anaesthesia. $\mathrm{Br} J$ Anaesth. 2008;101:627-631.

4) Shires GT. Important factors in the maintenance of homeostasis in the surgical patient. Acta Chir Scand Suppl. 1989;550:29-35.

5) De Jongh RF, Vissers KC, Booij LH, et al. Interleukin-6 and perioperative thermoregulation and HPA-axis activation. Cytokine. 2003;21:248-256.

6) Kurz A, Sessler DI, Narzt E, et al. Morphometric influences on intraoperative core temperature changes. Anesth Analg. 1995;80:562-567.

7) Roland CR, Goss JA, Mangino MJ, et al. Autoregulation by eicosanoids of human Kupffer cell secretory products. A study of interleukin-1, interleukin-6, tumor necrosis factor-alpha, transforming growth factor-beta, and nitric oxide. Ann Surg. 1994;219:389-399.

8) Fang JQ, Guo SY, Asano K, et al. Antipyretic action of peripheral stimulation with electroacupuncture in rats. In Vivo. 1998;12:503-510.

9) Higgins GM, Anderson RM. Experimental pathology of the liver, 1. Restoration of the liver of the white rat following partial surgical removal. Arch Pathol. 1931;12:186-202.

10) Wang B, Zhang Q, Zhu B, et al. Protective effect of gadolinium chloride on early warm ischemia/reperfusion injury in rat bile duct during liver transplantation. PLoS One (Internet). 2013;8:e52743 (accessed 2014 Dec 7) Available from: http://journals.plos.org/plosone/article?id=10.1371/journal.pone.0052743

11) Wu Y, Wang Y, Li M, et al. Gadolinium chloride suppresses acute rejection and induces tolerance following rat liver transplantation by inhibiting Kupffer-cell activation. Exp Ther Med. 2014;8:1777-1782.

12) Berasain C, Garcia-Trevijano ER, Castillo J, et al. Amphiregulin: an early trigger of liver regeneration in mice. Gastroenterology. 2005;128:424-432.

13) Goss JA, Mangino MJ, Flye MW. Kupffer cell autoregulation of IL-1 production by PGE2 during hepatic regeneration. J Surg Res. 1992;52:422-428.

14) Cartmell $\mathrm{T}$, Poole $\mathrm{S}$, Rothwell NJ, et al. Relationship between interleukin-1 and intreleukin-1 receptor antagonist during the development of fever in the rat. Ann N Y Acad Sci. 1998;29:252-255.

15) Saper CB, Breder CD. The neurologic basis of fever. N Engl J Med. 1994;330:1880-1886.

16) Simons CT, Kulchitsky VA, Sugimoto N, et al. Signaling the brain in systemic inflammation: which vagal branch is involved in fever genesis? Am J Physiol. 1998;275:R63-R68.

17) Tolba RH, Fet N, Yonezawa K, et al. Role of preferential cyclooxygenase-2 inhibition by meloxicam in ischemia / reperfusion injury of the rat liver. Eur Surg Res. 2014;53:11-24.

[Received November 8, 2014 : Accepted December 16, 2014] 